\title{
Relationship between cardiac injury, selected biochemical parameters, DIC, and hemogram levels in cattle with theileriosis')
}

\author{
OZLEM ORUNC KILINC*, NALAN OZDAL, KAMILE BICEK, M. SERDAR DEGER, \\ NAZMI YUKSEK ${ }^{* *}$, ALI BILGIN YILMAZ***, BEKIR OGUZ \\ Department of Parasitology, Faculty of Veterinary Medicine, Van Yuzuncu Yil University, Van, Turkey \\ *Van Yuzuncu Yil University, Ozalp Vocational School, Van, Turkey \\ **Department of Internal Diseases, Faculty of Veterinary Medicine, Van Yuzuncu Yil University, Van, Turkey \\ ***Van Yuzuncu Yil University, Van School of Health, TR-65090, Van, Turkey
}

Kilinc O. O., Ozdal N., Bicek K., Deger S. M., Yuksek N., Yilmaz A. B., Oguz B.

Relationship between cardiac injury, selected biochemical parameters, DIC, and hemogram levels in cattle with theileriosis

\section{Summary}

This study was undertaken to investigate the effects of theileriosis on the cardiovascular system in cattle. Blood samples were collected from 50 cattle naturally infected with Theileria spp. (before and after treatment) as well as from 30 non-infected cattle. Hematological parameters and the serum concentrations of total cardiac troponin I (cTnI), aspartate aminotransferase (AST), creatine kinase (CK), and creatine kinase MB (CK-MB) were measured. Also coagulation parameters, plasma levels of activated partial thrombo plastin time (APTT), prothrombin time (PT) and D-dimer were measured. The presence of anemia and the levels of cTnI, CK-MB, CK and AST indicated statistically significant differences between infected and healthy cattle, but no statistically significant differences between the two groups were found in DD levels at the end of the study. Reduction in anemia and reduced levels of cTnI, CK-MB, CK, AST, APTT and PT were also found in post-treatment analyses. The results indicate that anemia, coagulation disorders and hypoxia in theileriosis in cattle can induce myocardial tissue damage.

Keywords: theileriosis, cardiac troponin I, anemia, cattle, cardiac injury

Tick and tick-borne diseases of domesticated animals, particularly of sheep, goats, and cattle, cause substantial economic losses in tropical and sub-tropical regions $(6,13)$. Theileriosis is a disease caused by protozoan parasites of the genus Theileria that affects lymphocytes, erythrocytes, and macrophages $(7,11)$. One of the most important diseases of cattle in Turkey is tropical theileriosis caused by Theileria annulata, which is transmitted by ticks of the Hyalomma genus. Culture breed animals are more susceptible to the disease than native breed animals, and the disease leads to the loss of efficiency in highly efficient animals and death (2).

Troponins consist of 3 distinct myofibrillar proteins (I, C, and T), which regulate the calcium-mediated interaction between actin and myosin in both cardiac and skeletal muscles. Cardiac troponin I (cTnI) is the only

This research was supported by Van Yuzuncu Yil University Scientific Research Projects Presidency. (Project No: 2014-ÖMYO-B022). form that is uniquely expressed in the myocardium. Troponins and myoglobins are cardiac-originating proteins whose biochemical parameters are used to determine the existence and degree of myocardial injury. Creatinekinase (CK), lactate dehydrogenase (LDH), aspartate aminotransferase (AST), and alanine aminotransferase (ALT) are also used for this purpose, although they lack sensitivity and specificity (4).

$\mathrm{D}$-dimer is released as a result of fibrin degradation and is frequently used in the diagnosis of embolism. High D-dimer levels in blood suggest clotting in vessels, and therefore deep vein thrombosis, pulmonary embolism or DIC (disseminated intravascular coagulation) $(5,12)$. Hematological and coagulation parameters are useful criteria in the diagnosis and treatment of theileriosis.

Studies showing myocardial effects in protozoan diseases are very rare. However, cardiac involvement of some hemolytic infectious diseases, such as equine 
piroplasmosis and canine babesiosis, trypanosomiasis, primary immune-mediated hemolytic anemia and ehrlichiosis, has been studied $(8,14,17)$.

The aim of this study was to measure changes in serum levels of cTnI in myocardial damage, and to determine selected biochemical parameters (aspartate aminotransferase (AST), creatine kinase (CK) and creatine kinase-MB (CK-MB)) and plasma levels of coagulation parameters (activated partial thromboplastin time (APTT), prothrombin time (PT) and D-dimer) in cattle with clinical theileriosis, before and after treatment. The study also sought to establish whether changes in these parameters can be important criteria in determining the clinical diagnosis, pathology, severity and prognosis of theileriosis. This study is the first to measure the coagulation parameter D-dimer in theileriosis.

\section{Material and methods}

Clinical and parasitological examinations. The study was conducted on crossbred cattle in the province of Van in the Eastern Anatolia region of Turkey. The climate in the Van province is continental, with long cold snowy and rainy winters and short warm dry summers. The annual average temperature is about $9^{\circ} \mathrm{C}$, and the monthly averages are about $-3.5^{\circ} \mathrm{C}$ in January and $+22.3^{\circ} \mathrm{C}$ in July (19). Fifty crossbred cattle showing typical signs of theileriosis, such as tachycardia, fever, anemia, hematuria, and icterus, were chosen for this study. Their blood samples were collected into EDTA. The blood was used to prepare thin blood smears for microscopic examination and hematological analysis and to extract DNA for PCR analysis. Fixed blood smears from the ear tips of the cattle were prepared in methanol and stained with Giemsa stain in order to confirm the presence of Theileria parasites in Veterinary Teaching Hospital, Veterinary Faculty, Van Yuzuncu Yil University. Morphological and biometrical parameters, such as the shape and location of parasites in infected erythrocytes, were considered for differential diagnosis. Species identification was not performed in this study. All animals were presented to the Veterinary Teaching Hospital, Veterinary Faculty, Van Yuzuncu Yil University, Van, Turkey, from June 2013 to September 2015. A total of 30 clinically healthy cattle from tick-free farms were used as the control group.

Molecular analysis. DNA was extracted using a DNA isolation kit (Thermo) according to the manufacturer's instructions. Extracted DNA was stored at $4^{\circ} \mathrm{C}$ in a refrigerator. The primer sets used in this study were forward 5'-AGTTTC TGACCT ATCAG-3' reverse 5'-TTGCCT TAAACT TCCTTG-3' (1). For the amplification of the Theileria genus, 989F and 990R primers were used to amplify a 1098-bp fragment of the SSU rRNA gene. Polymerase Chain Reaction (PCR) was performed for $30 \mu$ lof total reaction volume containing $13.5 \mu 1$ of Promega DEPC water, $1.5 \mu 1$ of $\mathrm{MgCl}_{2}(25 \mathrm{mM} / \mathrm{ml}), 2.0 \mu 1$ of Promega dNTP, $2.5 \mu 1$ of $10 \times$ Taq buffer, $0.5 \mu 1$ of $50 \mathrm{u} / \mu 1$ Promega Taq polymerase, and $1.5 \mu 1$ of each primer and $2 \mu 1$ of template DNA. The reaction for the Theileria genus was repeated for 30 cycles under the following conditions: 5 minutes at $94^{\circ} \mathrm{C}, 30$ seconds at $94^{\circ} \mathrm{C}, 30$ seconds at $55^{\circ} \mathrm{C}, 45$ seconds at $72^{\circ} \mathrm{C}$, and 7 minutes at $72^{\circ} \mathrm{C}$. Agarose gel electrophoresis was used for the analysis of amplified DNA, and the results were visualized using a UV transilluminator.

Blood samples. Hematological, biochemical, and DD analyses were conducted on approximately $15-\mathrm{mL}$ blood samples collected from the jugular vein into vacutainers containing EDTA and sodium citrate as an anticoagulant or into anticoagulant-free serum tubes (for biochemical analysis). Hematological parameters were determined immediately. Platelet-poor plasma was obtained by centrifugation at $1600 \times \mathrm{g}$ for $20 \mathrm{~min}$ at $4^{\circ} \mathrm{C}$ and was analyzed within $1 \mathrm{~h}$. Serum was obtained by centrifugation at $3000 \times \mathrm{g}$ for $10 \mathrm{~min}$. Serum samples were preserved at $-20^{\circ} \mathrm{C}$ until analysis.

Hematological and D-dimer examinations. The total count of erythrocytes and hemoglobin and hematocrit levels were determined by automated cell counts (ACT-8 Coulter Miami-EUA). The plasma DD value was determined calorimetrically using commercial test kits (DD Kit Albio-Stago) by STA Compact.

Serum biochemical examinations. Serum cardiac troponin I (cTnI) values were determined calorimetrically using commercial test kits (Troponin I kitDRG Diagnostic) on an ELISA reader (ELISA Reader-DAS for cTnI). Serum AST and CK-MB levels were measured spectrophotometrically (Photometer 5010 Boehringer Mannheim) using commercial test kits (Randox-UK) as recommended by the manufacturers.

Treatment. After the collection of samples from infected animals, the animals were administered $2.5 \mathrm{mg} / \mathrm{kg}$ doses of buparvaquone, and twenty days later new blood samples were obtained to assess the same parameters and to compare them with their pre-treatment values. Blood samples were also taken from thirty healthy, tick-free cattle with normal body temperatures that comprised the control group.

Statistical analysis of the data. The descriptive statistics of the control and theileriosis groups were expressed as mean and standard deviation. The Student T-test was used to compare the theileriosis group with the control group. Statistical significance was set at $5 \%$, and the SPSS software bundle package 20 was used for calculations.

\section{Results and discussion}

The microscopic examination of the Giemsa-stained blood smears of infected cattle revealed the presence of free and intracellular forms. All samples positive by thin blood smears were also positive by PCR (Fig. 1). Hematological parameters assessed in blood samples obtained from infected animals were hematocrit ( $\mathrm{HtC})$, hemoglobin $(\mathrm{Hb})$, and red blood cell count levels, whereas the coagulation parameters assessed were the activated prothrombin time (APTT), prothrombin time (PT), and D-dimer levels. With regard to biochemical parameters, the cardiac troponin $(\mathrm{cTnI})$, creatine kinase $(\mathrm{CK})$, creatine kinase-MB (CK-MB), and aspartate aminotransferase (AST) levels were assessed. The mean values and standard deviations of all these parameters are presented in Tab. 1, which shows their levels in samples from animals before and after treatment and from the control group. 
The hematological analyses revealed that $\mathrm{Hct}, \mathrm{Hb}$, and RBC levels were decreased in infected animals. The comparison of Hct levels before and after treatment showed a statistically significant difference $(\mathrm{P}<0.05)$. However, a statistically significant $(\mathrm{P}<0.05)$ difference was also identified between the pre-treatment levels and the control group levels. The comparison of the pre-treatment APTT and PT levels in the infected group with the levels of these parameters in the control group showed a statistically significant difference $(\mathrm{P}<0.01$ and $\mathrm{P}<0.05$, respectively). No difference was identified between the D-dimer levels of the three groups. As regards cTnI, AST, and CK levels, statistically significant differences were present before and after treatment $(\mathrm{P}<0.05$, $\mathrm{P}<0.05$, and $\mathrm{P}<0.001$, respectively). The values of these parameters were high in the infected group.

A statistically significant difference was also detected between the pre-treatment group and the control group in terms of cTnI, AST, CK-MB and CK levels. The parameters studied and the statistical differences between the groups are presented in Tab. 1.

Theileriosis, a disease caused by the Theileria genus, results in acute death in farm animals. Its main signs are anemia, fever, respiratory failure, swollen lymph nodes, and hypoxia. Many studies report these findings in animals with theileriosis $(6,9,18,19)$. In



Fig. 1. Detection of Theleria spp. in blood samples by the PCR assay

Explanations: Lanes M: molecular size marker (Qiagen, Germany); Lanes 1: negative control; Lanes P: positive control; Lanes 2: positive PCR products of Theileria spp. ab. 1. Hematological and biochemical parameters in clinically healthy cattle and cattle infected with Theileria spp. (before and after treatment)

\begin{tabular}{|l|c|c|c|}
\hline $\begin{array}{c}\text { Parameters } \\
\text { analyzed }\end{array}$ & $\begin{array}{c}\text { Control group } \\
\mathrm{n}=30\end{array}$ & $\begin{array}{c}\text { Pre-treatment group } \\
\mathrm{n}=50\end{array}$ & $\begin{array}{c}\text { Post-treatment group } \\
\mathrm{n}=50\end{array}$ \\
\hline $\mathrm{Hct}(\%)$ & $29.80 \pm 0.56^{\mathrm{a} *}$ & $23.44 \pm 0.67^{\mathrm{ab}}$ & $26.51 \pm 0.98^{\mathrm{b} *}$ \\
$\mathrm{Hg}(\mathrm{g} / \mathrm{dL})$ & $10.21 \pm 0.42^{\mathrm{a} *}$ & $8.91 \pm 0.50^{\mathrm{a}}$ & $10.05 \pm 0.26$ \\
$\mathrm{RBC}\left(\times 10^{3}\right)$ & $7.13 \pm 0.15^{\mathrm{a} *}$ & $5.63 \pm 0.27^{\mathrm{a}}$ & $6.77 \pm 0.13$ \\
APTT $(\mathrm{sn})$ & $32.50 \pm 2.49^{\mathrm{a} * *}$ & $45.53 \pm 3.2^{\mathrm{a}}$ & $44.26 \pm 1.67 \mathrm{a}$ \\
PT $(\mathrm{sn})$ & $22.22 \pm 0.50^{\mathrm{a} *}$ & $26.16 \pm 1.68 \mathrm{a}$ & $24.78 \pm 0.42$ \\
DD $(\mu \mathrm{g} / \mathrm{ml})$ & $0.53 \pm 0.08$ & $0.48 \pm 0.07$ & $0.45 \pm 0.07$ \\
CTnl $(\mathrm{ng} / \mathrm{mL})$ & $0.055 \pm 0.02^{\mathrm{a} *}$ & $0.14 \pm 0.02^{\mathrm{ab}}$ & $0.057 \pm 0.01^{\mathrm{b} *}$ \\
CK $(\mathrm{U} / \mathrm{L})$ & $153.77 \pm 24.91^{\mathrm{a} * * *}$ & $839.13 \pm 84.37^{\mathrm{ab}}$ & $246.50 \pm 25.79^{\mathrm{b} * * *}$ \\
\hline CK-MB $(\mathrm{U} / \mathrm{L})$ & $211.75 \pm 23.40^{\mathrm{a} *}$ & $268.86 \pm 27.55^{\mathrm{a}}$ & $243.13 \pm 15.83$ \\
\hline AST $(\mathrm{U} / \mathrm{L})$ & $66.75 \pm 3.89^{\mathrm{a} *}$ & $83.60 \pm 4.06^{\mathrm{ab}}$ & $76.55 \pm 3.40^{\mathrm{b} *}$ \\
\hline
\end{tabular}

Explanations: $\mathrm{a}, \mathrm{b}-$ means with different superscript letters differ significantly at $* \mathrm{P}<0,05, * * \mathrm{P}<0,01, * * * \mathrm{P}<0,001$

this study, as well, infected animals exhibited general signs of theileriosis.

Glass et al. (11) report that anemia in cattle with theileriosis is extravascular. These researchers believe that the toxic metabolites of the causative agent affect the bone marrow and disrupt erythropoiesis, and that tumor necrosis factor- $\alpha$ (TNF- $\alpha$ ) may also be the cause of anemia. We also identified a clinical picture of anemia with low Hct, $\mathrm{RBC}$, and $\mathrm{Hb}$ in infected animals in the present study. These findings are consistent with previous studies $(6,9,18,19)$.

Col and Uslu (6) report that APTT and PT levels are higher in cattle with theileriosis when compared to healthy animals. These researchers also report that theileria agents cause lesions in the form of multiple petechial hemorrhages in the liver, lungs, and kidneys. These lesions cause coagulation defects. Glass et al. (10) note that cytokines, such as TNF- $\alpha$, interleukin-1 and interleukin-6, and mediators, such as neutrophil esterase and free oxygen radicals released from macrophages and monocytes infected with schizonts, disrupt the coagulation mechanism. In the present study, in infected animals, APTT levels were $45.53 \pm 3.2$, and the PT levels were $26.16 \pm 1.68$, whereas in the control group, the APTT levels were $32.50 \pm 2.49$, and the PT levels were $22.22 \pm 0.50$. The bleeding time was longer in infected animals. D-dimer is a substance formed by fibrin degradation. In this study, no statistically significant differences were found between the groups in D-dimer levels.

The serum AST and CK levels were measured in infected cattle before and after treatment. Analyses showed that these levels were higher than those in the control group and that they dropped after treatment. While the AST level was $83.60 \pm 4.06$ and the CK level was $839.13 \pm 84.37$ before treatment, they decreased to $76.55 \pm 3.40$ and $246.50 \pm 25.79$, respectively, after treatment. These findings are consistent with those of previous similar studies $(3,9,18)$. 
The number of studies on heart injury in parasitic diseases is very low. There are many hypotheses about the development of heart injury in animals with theileriosis. Studies conducted on this subject suggest that the toxins of theileria agents, cytokines, and free oxygen radicals that form during infections may cause myocyte injury. It is also argued that the hypoxia resulting from anemia and the vasculitis caused by the agent may also lead to myocyte injury in theileriosis. Researchers support this opinion by reporting that $\mathrm{cTnI}$ levels increase in indirect proportion to dropping hematocrit levels $(9,19)$. Similar results have also been reported in other protozoal diseases that cause anemia $(8,16)$. In this study, Hct, Hb, and RBC levels in infected cattle dropped with the development of anemia, while cTnI and CK-MB levels increased. Moreover, the levels of these parameters dropped in parallel with the resolution of anemia after treatment.

In conclusion, in the present study on cattle with theileriosis, a significant increase was detected in the levels of cTnI, CK-MB, CK and AST, which, together with anemia, are important in the diagnosis of cardiac injury. The analysis of the levels of these parameters supports the opinion that Theileria spp. and hypoxia due to infection could cause cardiac injury. The reduction in these levels after treatment confirms this hypothesis.

\section{References}

1.Ariyaratne-De M. E. S. A., Gothami W. S., Rajapakse R. V. P. J.: Application of PCR technique on confirming Theileria infection in cattle and buffaloes with determining the relationship between Animals' PCV and WBC count with the infection. Int. J. Sci. Res. 2014, 4, 1-4.

2. Aysul N., Karagenc T., Eren H., Aypak S., Bakırcı S.: Aydın ili sığırlarında tropikal theileriosisin yaygınlığı ve Theileria annulata şizont aşısının sahada etkinliğinin değerlendirilmesi. Türkiye Parasitol. Derg. 2008, 32, 322-327.

3. Basbug O., Gul Y.: Tropikal Tayleriyozisli sı̆̆ırlarda hemoliz üzerine araştırmalar. Kafkas Univ.Vet. Fak. Derg. 2011, 17, 421-427.
4. Basbugan Y., Agaoglu Z., Yuksek N.: An investigation on serum troponin concentration in healthy ruminants. Kafkas Univ. Vet. Fak. Derg. 2010, 16, 641-645.

5. Cassar K., Bachoo P., Ford I., Greaves M., Brittened J.: Clopidogrel has no effect on D-dimer and thrombin-antithrombin III levels in patients with peripheral arterial disease undergoing peripheral percutaneous transluminal angioplasty. J. Vasc. Surg. 2005, 42, 252-258.

6. Çol R., Uslu U.: Haematological and coagulation profiles during severe tropical theileriosis in cattle. Turk. J. Vet. Anim. Sci. 2006, 30, 577-582.

7. Dabak M., Dabak D. O., Aktas M.: Cerebral theileriosis in a Holstein calf. Vet. Rec. 2004, 154, 533-534.

8.Diana A., Guglielmini C., Candinin D., Pietra M., Cipone M.: Cardiac arrhythmi assassociated with piroplasmosis in the horse: A case report. Vet. J. 2007, 174, 193-195.

9. Fartashvand M., Nadalian M. G., Sakha M., Safi S.: Elevated serum cardiac troponin I in cattle with theileriosis. J. Vet. İntern. Med. 2013, 27, 194-199.

10. Glass E. J., Craigmile S. C., Springbett A., Preston P. M., Kirvar E., Wilkie G. M., Eckersall P. D., Hall F. R., Brown C. G. D.: The protozoan parasite, Theilaria aannulata, induces a distinct acute phase protein response in cattle that is associated with pathology. Int. J. Parasitol. 2003, 33, 1409-1418.

11. Glass E. J., Innes E. A., Spooner R. L., Brown C. G. D.: Infection of bovine monocyte/macrophage populations with Theileria annulata and Theileria parva. Vet. Immunol. Immunopathol. 1989, 22, 355-368.

12. Goehring L. S., Hussey S., Gomez-Diez M., Benedct K., Maxwell L. K., Morley P. S., Sloet M. M., Lunn D. P.: Plasma D-dimer concentrations during experimental EHV-1 infections of horses. J. Vet. Intern. Med. 2013, 27, 1535-1542.

13. Inci A., Iça A., Yildirim A., Vatansever Z., Çakmak A., Albasan H., Çam Y., Atasever A., Düzlü Ö.: Epidemiology of tropical theileriosis in the Cappadocia region. Türk J. Vet. Anim. Sci. 2008, 32, 57-64.

14. Jacobson L. S., Clark I. A.: The pathophysiology of canine babesiosis: New approaches to an old puzzle. J. S. Afr. Vet. Assoc. 1994, 65, 134-145.

15. Kalelioglu E.: Characteristics of the climate of Van Plain (Van Ovasının iklim özellikleri). Ankara Üniv. Dil Tarih-Coğrafya Fak. Derg. 1991, 35, 155-166.

16. Kilinc O. Ö., Goz Y., Yüksek N., Basbugan Y., Yilmaz A. B.,. Ataş A. D.: Determination of serum cardiac biomarkers and plasma D-dimer levels in anemic sheep with babesiosis. Turk. J. Vet. Anim. Sci. 2015, 39, 606-610.

17. Lobetti R., Dvir E., Pearson J.: Cardiac troponins in canine babesiosis. J. Vet. Intern. Med. 2002, 16, 63-68.

18. Pasa S.: Theileriosis'li sı̆̆ırlarda buparvaquone (Buparvan)'ın terapotik etkinliği. Turk. Parasitol. Derg. 2008, 32, 317-321.

19. Razavi S. M., Nazifi S., Hasani S., Rakhshandehroo E.: Bovine tropical theileriosis: effects on the cardiovascular system on the basis of serum analysis. Comp. Clin. Pathol. 2015, 24, 29-33.

Corresponding author: Bekir Oguz, Assoc. Prof. DVM, Faculty of Veterinary Medicine, Department of Parasitology, 65100, Tusba, Van, Turkey; e-mail: bekiroguz@yyu.edu.tr 